\title{
Isolation of subgenus B adenovirus during a fatal outbreak of enterovirus 71-associated hand, foot, and mouth disease in Sibu, Sarawak
}

\author{
M Jane Cardosa, Shekhar Krishnan, Phaik Hooi Tio, David Perera, See Chang Wong
}

\section{Summary}

Background In mid-1997, several children died in Sarawak, Malaysia, during an epidemic of enterovirus-71 (EV71) hand, foot, and mouth disease. The children who died had a febrile illness that rapidly progressed to cardiopulmonary failure and the cause was not satisfactorily resolved. We describe the is olation and identification of a subgenus $B$ adenovirus from the children who died.

Methods We studied two groups of children presenting to Sibu Hospital from April 14 to Sept 30, 1997. For children who died, the inclusion criterion was death after febrile illness, and for those who did not die it was acute flaccid paralysis (AFP). Serum and cerebrospinal fluid samples were tested for IgM antibodies to Japanese encephalitis and dengue viruses. Viruses isolated were identified by immunofluorescence, reversetranscriptase PCR, or PCR and DNA sequencing.

Findings Enterovirus was isolated in three (19\%) of 16 children who died and in none of the eight surviving children with AFP. However, an agent that was initially difficult to identify was found in ten (63\%) children who died and five $(63 \%)$ surviving children who had AFP. The agents is olated from ten $(66.7 \%)$ of these 15 children were eventually identified as adenoviruses and were isolated mainly from clinically important sterile sites or tissues. All the enteroviruspositive children who died had this second agent.

Interpretation Our data raises doubts that EV71 was the only aetiological agent in these deaths.

Lancet 1999; 354: 987-91

\section{Introduction}

On April 14, 1997, a boy aged 19 months presented with acute shock after a brief unremarkable febrile illness. Acute myocardial dysfunction with cardiogenic shock was suspected when fluid resuscitation led to pulmonary oedema and echocardiogram showed a poorly contractile globular left ventricle. D uring the next 4-5 months, several children presented with a brief prodromal febrile illness followed by rapid deterioration with cardiogenic shock and death refractory to supportive care.

T wo children, who were among the first to die, had acute flaccid paralysis (AFP). Concurrently, a greater number than normal (two or three cases a year) of poliovaccinated children with uncomplicated AFP was noted. The temporal association of acute myocardial dysfunction with AFP and aseptic meningitis in the context of hand, foot, and mouth disease suggested a major enterovirus epidemic in the community, and formal epidemiological and virological investigations were started by the Sarawak $\mathrm{H}$ ealth D epartment at the end of M ay, 1997.

It has been 2 years since this cluster of paediatric deaths occurred in Sarawak, M alaysia. ${ }^{1,2} \mathrm{~T}$ he deaths of at least 34 children aged 5 months to 7 years (mean age 20 months) were reported during a period of less than 5 months. H owever, a clear consensus on cause has been difficult to reach because the unusual presentation of cardiomyopathy with encephalitis occurred against a background of enterovirus-71 (EV71) hand, foot, and mouth disease (seven of 12 enteroviruses isolated from children with this disease were EV71; unpublished data). A similar episode took place a year ago in T aiwan and the aetiological agent associated with the deaths is still under investigation. ${ }^{3}$

We will focus on patients admitted to Sibu H ospital, the only hospital serving Sibu town, where this unusual outbreak was first recognised and where 20 of the 34 recorded child deaths occurred. Sibu town has a population of 200000 and is situated at the gateway to the Rejang Valley in the heart of Sarawak. The hospital also serves as a referral hospital for smaller district hospitals in the Rejang basin. The first nine deaths in the Sarawak outbreak occurred in Sibu H ospital, with Sibu town as the epicentre of the outbreak which, by mid June, had spread to other parts of Sarawak.

\section{Methods}

We included two groups of patients in our study: children in whom unexplained sudden paediatric death after a febrile illness was the only inclusion criterion, and children with AFP during the outbreak who did not die. Both groups were admitted to Sibu H ospital from A pril 14 to the end of September, 1997.

Samples obtained were mainly from serum, cerebrospinal fluid, throat swabs, and rectal swabs. These samples were inoculated onto or cocultivated with monolayers of rhabdomyosarcoma (RD) cells, human pulmonary adenocarcinoma (A549) cells, African green-monkey kidney (Vero) cells, and A edes albopictus (C 6/36) cells in flat tissue-culture tubes (N unc, Roskilde, Denmark), and 
observed daily for cytopathic effect. All cultures were subjected to one blind passage in the same four cell lines. We used PCR or reverse-transcriptase (RT) PCR to identify cultures that were positive for enterovirus or adenovirus. RT-PCR was used to identify flaviviruses only if a characteristic cytopathic effect was seen in C $6 / 36$ cells. Direct immunofluorescence for adenovirus and herpes simplex virus types 1 and 2 was done with Dako I magen reagents (Ely, UK)

Viral nucleic acids were extracted from freeze-thawed cultures by QIAamp viral RNA kit (Qiagen, H ilden, Germany) or a high pure viral nucleic-acid extraction kit (Boehringer $M$ annheim, $M$ annheim, Germany) and were used as templates for RT-PCR or PCR. The oligonucleotide primers used were based on previously published sequences ${ }^{4-6}$ and were synthesised by Genemed Synthesis (San Francisco, CA, USA). For adenovirus identification, the forward primer was 5'-GCCGCAGTGGTCTTACATGCACATC-3' and the reverse primer was $5^{\prime}$-CAGCACGCCGCGGAT GT CAAAGT$3^{\prime}$, which gave an expected product size of $301 \mathrm{bp}^{4}$ For enterovirus identification, the forward primer was $5^{\prime}$ ATTGTCACCATAAGCAGCCA-3' and the reverse primer was 5'-CCTCCGGCCCCTGAATGCGGCTAAT -3', which gave a product of $154 \mathrm{bp} .{ }^{5}$ The presence of flavivirus genome was detected by universal flavivirus primers that were expected to give variable product sizes depending on the flavivirus. The forward primer was $5^{\prime}$-GGTCTCCTCTAACCT CTAG-3' and the reverse primer was $5^{\prime}$-GAGTGGATGACCACGGAAGACATGC $-3^{\prime} .^{6}$ The cycling conditions used for amplification have been described previously (unless stated otherwise).

EV71 was identified by oligonucleotide primers (cycling conditions generously provided by M Pallansch, CDC, Atlanta, GA, USA). We also submitted some adenoviruses and non-EV71 enteroviruses to the pathology department of Singapore General H ospital for typing by standard neutralisation assays. Some cultures were positive for adenoviruses by immunofluorescence, but the viruses were difficult to grow sufficiently well for neutralisation tests. PCR products from these fastidious adenoviruses that were identified were cloned by use of the Zero Blunt cloning kit (Invitrogen, Carlsbad, CA, USA) and inserts were sequenced in both directions by a sequencing service (ACGT, N orthbrook, IL, USA) by ABI-100 version 3.0. All serum and cerebrospinal-fluid samples were tested for IgM antibodies to Japanese encephalitis and dengue viruses. ${ }^{7,8} \mathrm{We}$ further characterised three of the fastidious adenoviruses by restriction digestion of a virus-associated (VA) RNA gene region PCR product using previously described methods. ${ }^{9}$

\section{Results}

We obtained specimens from 16 of the 20 children who died and from all of the eight surviving children with AFP seen in Sibu H ospital during the outbreak period (A pril to September, 1997). Only three (19\%) of the 16 children who died and none of the surviving children with AFP yielded enteroviruses in culture. One of the enteroviruses isolated from the serum of child who died was typed as echovirus type 25 (Chan K wai Peng, Singapore General $\mathrm{H}$ ospital, personal communication), whereas the other two had EV71 (serum and rectal swab in one patient and throat swab in the other).

Other viruses isolated from fatal-case samples were dengue virus (type 3) from cerebrospinal fluid and herpes simplex virus type 2 from mouth-ulcer swab. O ne patient was flavivirus positive in cerebrospinal fluid by RT -PCR, although we did not isolate in culture a flavivirus or any other agent from this patient. All patients tested negative for IgM to Japanese encephalitis and dengue viruses.

$C$ ytopathic effect was seen in long-passage material from A549 cells inoculated with samples in 15 patients: ten $(63 \%)$ of 16 children who died and five $(63 \%)$ of eight surviving children with AFP. The identification of this agent was difficult because it was hard to grow in sufficient
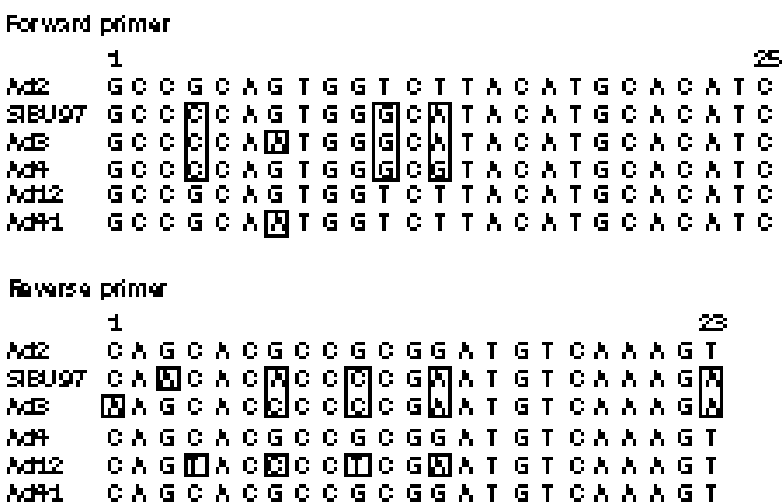

Figure 1: Alignment of forward and reverse primer priming sites Mismatches to Allard primer sequences ${ }^{4}$ are boxed. Genbank accession numbers: Ad2, J01917; Ad3, X76549; Ad4, AF065064; Ad12, X73487; Ad41, D13781.

amounts for standard neutralisation assays. We have called it "agent $Y$ " because a still unidentified agent isolated by CDC scientists from specimens obtained from the same patient group has been designated "agent $X$ " (unpublished CDC reports to the Ministry of Health, Government of $M$ alaysia). Samples from all the AFP cases had also been submitted to the poliovirus surveillance laboratory at the Institute for M edical Research in K uala Lumpur, but no poliovirus or other enterovirus infection was reported for any of these children.

At least six of eight agent $Y$ isolates tested by immunofluorescence were weakly positive for adenoviruses, but confirmation by PCR was initially negative. Stringency of the PCR conditions was reduced by lowering the annealing temperature from $54^{\circ} \mathrm{C}$ to $50^{\circ} \mathrm{C}$ and increasing the number of cycles from 40 to 45 . PCR product was initially obtained in this manner for three agent $Y$ isolates and these products were cloned and sequenced. A BLAST search of the GenBank sequence database ( $\mathrm{NCBI}$, Bethesda, MD, USA) showed that these agent $Y$ isolates were $92 \%$ homologous with adenovirus type 16 in this region of the hexon gene. Interestingly, the sequence of the PCR product from an untypable adenovirus isolated from the cerebrospinal fluid and stool samples of a child with AFP (aged 13 months) from Singapore was found to be almost identical to that of the adenoviruses isolated from children in Sibu. This adenovirus was neutralised by antisera to adenovirus types 11,34 , and 35 . EV 71 was also isolated from stool samples but not cerebrospinal fluid from this patient ( $\mathrm{C}$ han $\mathrm{K}$ wai Peng, Singapore G eneral $\mathrm{H}$ ospital, Singapore, personal communication). The sequences of representative PCR products have been deposited with the European Molecular Biology Laboratory ( $\mathrm{H}$ inxton, Cambridge, UK) and have accession numbers AJ005423, AJ011574, and AJ011575.

We obtained the complete sequence of the hexon gene from the first of our agent $Y$ isolates from the tenth child who died, which we have designated SIBU 97 (accession number AJ012091). We submitted this sequence to a BLAST search of $\mathrm{G}$ enBank and the best three matches returned were the subgenus B adenoviruses type 7 ( $87 \%$ homology), type 3 (86\% homology), and type 16 ( $83 \%$ homology).

$T$ he primers initially used to detect adenovirus genome in the agent $Y$ cultures ${ }^{4}$ were compared with the hexon sequence of SIBU 97 and found to have multiple mismatches in the priming sites for both primers (three of 25 in the forward primer and five of 23 in the reverse primer). The alignment of the priming sites in 


\begin{tabular}{|c|c|c|c|c|c|c|c|c|c|c|c|}
\hline \multirow[t]{2}{*}{ Patient } & \multirow{2}{*}{$\begin{array}{l}\text { Age } \\
\text { (months) }\end{array}$} & \multirow[t]{2}{*}{ Sex } & \multicolumn{2}{|l|}{ Date* } & \multirow{2}{*}{$\begin{array}{l}\text { Presentation and } \\
\text { echocardiography }\end{array}$} & \multirow[t]{2}{*}{ Viral prodromet } & \multirow{2}{*}{$\begin{array}{l}\text { CSF } \\
\text { analysis }\end{array}$} & \multirow{2}{*}{$\begin{array}{l}\text { Specimens } \\
\text { on admission }\end{array}$} & \multirow{2}{*}{$\begin{array}{l}\text { Necropsy } \\
\text { samples } \neq\end{array}$} & \multirow{2}{*}{$\begin{array}{l}\text { Histopathological } \\
\text { examination }\end{array}$} & \multirow[t]{2}{*}{ Virus (specimen) } \\
\hline & & & Presented & Died & & & & & & & \\
\hline 1 & 19 & Male & Apr 14 & Apr 15 & $\begin{array}{l}\text { Shock, respiratory } \\
\text { failure, PCGLV }\end{array}$ & $\begin{array}{l}\text { Yes, no HFM } \\
\text { lesions }\end{array}$ & No CSF & None & None & $\cdot$. &. \\
\hline 2 & 9 & Female & Apr 20 & Apr 21 & $\begin{array}{l}\text { Possible seizure, } \\
\text { RUL AFP, } \\
\text { cardiopulmonary } \\
\text { failure } 10 \mathrm{~h} \text { after } \\
\text { admission, PCGLV }\end{array}$ & $\begin{array}{l}\text { Yes, no HFM } \\
\text { lesions }\end{array}$ & CSF split & None & None & .. & .. \\
\hline 3 & 6 & Male & Apr 23 & Apr 23 & $\begin{array}{l}\text { Cardiopulmonary } \\
\text { failure/ arrest in ER, } \\
\text { PCGLV }\end{array}$ & $\begin{array}{l}\text { Yes, no HFM } \\
\text { lesions }\end{array}$ & No CSF & None & None & $\cdot$. & $\cdot$. \\
\hline 4 & 34 & Female & May 4 & May 4 & $\begin{array}{l}\text { Headaches, vomiting, } \\
\text { clouded sensorium, } \\
\text { cardiovascular } \\
\text { collapse } 1 \text { h after } \\
\text { admission, PCGLV }\end{array}$ & $\begin{array}{l}\text { Yes, no HFM } \\
\text { lesions }\end{array}$ & ASM & Serum, CSF & None & .. & No growth \\
\hline 5 & 8 & Female & May 5 & May 6 & $\begin{array}{l}\text { RUL AFP, right ptosis, } \\
\text { shock, PCGLV }\end{array}$ & $\begin{array}{l}\text { Yes, macular rash } \\
\text { on lower limbs }\end{array}$ & ASM & Serum, CSF & None & .. & $\begin{array}{l}\text { No growth, RT-PCR } \\
\text { possible for flavivirus } \\
\text { from CSF }\end{array}$ \\
\hline 6 & 44 & Female & May 8 & May 8 & $\begin{array}{l}\text { Cardiopulmonary } \\
\text { failure, ventricular } \\
\text { arrhythmias, PCGLV }\end{array}$ & $\begin{array}{l}\text { Yes, no HFM } \\
\text { lesions }\end{array}$ & No CSF & Serum & None & .. & Agent $Y$ \\
\hline 7 & 22 & Female & May 14 & May 14 & $\begin{array}{l}\text { Vomiting, seizure, } \\
\text { shock, PCGLV }\end{array}$ & $\begin{array}{l}\text { Yes, mouth } \\
\text { ulcers }\end{array}$ & No CSF & Serum & None & .. & $\begin{array}{l}\text { Echovirus } 25 \text { and } \\
\text { agent } Y \text { (Ad by nested } \\
\text { PCR) from serum }\end{array}$ \\
\hline 8 & 15 & Male & May 25 & May 28 & $\begin{array}{l}\text { Cardiopulmonary } \\
\text { failure, PCGLV }\end{array}$ & $\begin{array}{l}\text { Yes, no HFM } \\
\text { lesions }\end{array}$ & No CSF & None & None & .. & .. \\
\hline 9 & 19 & Male & May 28 & May 28 & $\begin{array}{l}\text { Shock, PCGLV } \\
\text { (video recording } \\
\text { available)§ }\end{array}$ & Yes, HFM & No CSF & $\begin{array}{l}\text { Serum, } \\
\text { RS, TS }\end{array}$ & None & $\cdot$. & $\begin{array}{l}\text { EV71 from serum, } \\
\text { RS, agent Y (SIBU97) } \\
\text { from serum }\end{array}$ \\
\hline 10 & 5 & Male & $\cdot$. & May 29 & Brought in dead & $\begin{array}{l}\text { Yes, no HFM } \\
\text { lesions }\end{array}$ & No CSF & .. & $\begin{array}{l}\text { Serum, CSF, } \\
\text { TS, RS }\end{array}$ &.$\cdot$ & $\begin{array}{l}\text { Agent Y (SIBU97) } \\
\text { from CSF, characterised } \\
\text { as subgenus B } \\
\text { adenovirus }\end{array}$ \\
\hline 11 & 10 & Male & May 29 & May 30 & $\begin{array}{l}\text { Seizures, } \\
\text { cardiopulmonary } \\
\text { failure } 10 \mathrm{~h} \text { after } \\
\text { admission, PCGLV }\end{array}$ & Yes, HFM & ASM & $\begin{array}{l}\text { Serum, CSF, } \\
\text { TS, RS }\end{array}$ & None & .. & $\begin{array}{l}\text { EV (not typed) } \\
\text { from serum, agent } Y \\
\text { from TS }\end{array}$ \\
\hline 12 & 53 & Male & May 1 & May 1 & Shock, PCGLV & Yes, HFM & .. & $\begin{array}{l}\text { Serum, CSF, } \\
\text { TS, RS }\end{array}$ & None & .. & Agent $Y$ from TS \\
\hline 13 & 8 & Male & $\cdot \cdot$ & June 1 & Brought in dead & $\begin{array}{l}\text { Yes, no HFM } \\
\text { lesions, escar } \\
\text { on buttock }\end{array}$ &.. & .. & $\begin{array}{l}\text { Serum, CSF, } \\
\text { TS, RS }\end{array}$ & .. & $\begin{array}{l}\text { Dengue } 3 \text { in CSF, } \\
\text { agent } Y \text { (SIBU97) } \\
\text { from TS, CSF }\end{array}$ \\
\hline 14 & 22 & Female & June 5 & June 5 & $\begin{array}{l}\text { Seizure, cardio- } \\
\text { pulmonary arrest } \\
\text { witnessed by primary-care } \\
\text { physician, brought } \\
\text { in dead }\end{array}$ & Yes, HFM & Normal & .. & $\begin{array}{l}\text { Intracardiac } \\
\text { blood, CSF } \\
\text { TS, RS }\end{array}$ &.$\cdot$ & No growth \\
\hline 15 & 18 & Female & June 9 & June 10 & $\begin{array}{l}\text { Drowsy, lethargy, } \\
\text { shock } 16 \text { h after } \\
\text { admission, PCGLV }\end{array}$ & Yes, HFM & ASM & Serum, CSF & $\begin{array}{l}\text { Cardiac muscle } \\
\text { biopsy }\end{array}$ & $\begin{array}{l}\text { Cardiac muscle } \\
\text { normal }\end{array}$ & $\begin{array}{l}\text { Agent Y (Ad by IF) from } \\
\text { cardiac muscle, agent } Y \\
\text { (Ad by IF) from CSF } \\
\text { of sibling survivor }\end{array}$ \\
\hline 16 & 22 & Male & June 10 & June 11 & $\begin{array}{l}\text { Acute cardiovacular } \\
\text { collapse, PCGLV }\end{array}$ & Yes, HFM & ASM & Serum, CSF & $\begin{array}{l}\text { Intracardiac } \\
\text { blood, cardiac } \\
\text { muscle biopsy }\end{array}$ & $\begin{array}{l}\text { Cardiac muscle } \\
\text { normal }\end{array}$ & $\begin{array}{l}\text { No growth, IgG and } \\
\text { seroconversion shown } \\
\text { against SIBU97 }\end{array}$ \\
\hline 17 & 22 & Male & June 11 & June 13 & $\begin{array}{l}\text { Lethargy, shock, } \\
\text { LVEF } 30 \% \text { at admission, } \\
\text { ventricular dys rhythmias } \\
\text { before death }\end{array}$ & Yes, HFM & ASM & Serum, CSF & $\begin{array}{l}\text { Cardiac muscle } \\
\text { biopsy; } \\
\text { liver biopsy }\end{array}$ & $\begin{array}{l}\text { Cardiac muscle, } \\
\text { liver normal }\end{array}$ & No growth \\
\hline 18 & 27 & Male & June 23 & June 24 & $\begin{array}{l}\text { Vomiting, acute } \\
\text { cardiopulmonary } \\
\text { failure } 6 \mathrm{~h} \text { after } \\
\text { admission, PCGLV }\end{array}$ & Yes, HFM & ASM & $\begin{array}{l}\text { Serum, CSF, } \\
\text { RS, TS }\end{array}$ & $\begin{array}{l}\text { Liver, lung, } \\
\text { spleen, } \\
\text { adrenals, } \\
\text { brain, heart, } \\
\text { kidney }\end{array}$ & $\begin{array}{l}\text { ASM and } \\
\text { encephalitis, } \\
\text { normal heart, } \\
\text { lung congestion } \\
\text { and oedema }\end{array}$ & $\begin{array}{l}\text { Agent Y (Ad by PCR) } \\
\text { from brain, heart, } \\
\text { and lung }\end{array}$ \\
\hline 19 & 7 & Female & June 23 & June 28 & $\begin{array}{l}\text { Acute cardiopulmonary } \\
\text { failure/ arrest, PCGLV }\end{array}$ & $\begin{array}{l}\text { Yes, no HFM } \\
\text { lesions }\end{array}$ & ASM & $\begin{array}{l}\text { Serum, CSF, } \\
\text { RS, TS }\end{array}$ & $\begin{array}{l}\text { Brain, heart, } \\
\text { liver biopsy }\end{array}$ & $\begin{array}{l}\text { Normal } \\
\text { myocardium, focal } \\
\text { hepatic necrosis, } \\
\text { vascular congestion } \\
\text { in brain }\end{array}$ & No growth \\
\hline 20 & 33 & Male & June 29 & June 29 & Shock, PCGLV & $\begin{array}{l}\text { Yes, mouth ulcers, } \\
\text { macular rash on } \\
\text { buttocks/ right palm }\end{array}$ & ASM & $\begin{array}{l}\text { Serum, CSF, } \\
\text { mouth ulcer } \\
\text { swab, RS, TS }\end{array}$ & $\begin{array}{l}\text { Heart, } \\
\text { liver biopsy }\end{array}$ & $\begin{array}{l}\text { Normal cardiac } \\
\text { and liver tissue }\end{array}$ & $\begin{array}{l}\text { HSV-2 from mouth } \\
\text { ulcer, agent Y (SIBU97) } \\
\text { from CSF and heart; } \\
\text { sibling had EV71 HFM }\end{array}$ \\
\hline
\end{tabular}

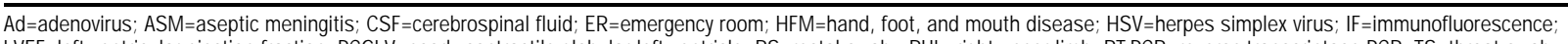
$\mathrm{LVEF}=$ left ventricular ejection fraction; PCGLV=poorly contractile globular left ventricle; $R S=$ =rectal $s$ wab; RUL=right upper limb; RT-PCR=reverse-trans criptase PCR; TS=throat $s$ wab. *All 1997. WWhen it was apparent that there was a large outbreak of HFM in the community, children with rash on the extremities or mouth ulcers were clinically diagnosed as having HFM. ‡Consent for full necropsy was given for only one patient (18); tissue samples obtained from some other patients were throughcut biopsies. §Available from Lancet website (www.thelancet.com).

Table 1: Fatal cases

representative adenovirus serotypes indicates that these primers are unsuitable for use with other subgenus B adenoviruses (figure 1).
To improve detection of this fastidious adenovirus in agent $Y$ cultures, we synthesised primers for nested PCR based on the sequence we obtained for SIBU 97. The outer 


\begin{tabular}{|c|c|c|c|c|c|c|c|c|c|}
\hline Patient & $\begin{array}{l}\text { Age } \\
\text { (months) }\end{array}$ & Sex & $\begin{array}{l}\text { Date* } \\
\text { presented }\end{array}$ & Presentation & Viral prodrome & $\begin{array}{l}\text { CSF } \\
\text { analysis }\end{array}$ & $\begin{array}{l}\text { Samples on } \\
\text { admission }\end{array}$ & Outcome & Virus (specimen) \\
\hline 1 & 12 & $\overline{\text { Female }}$ & May 2 & Acute diarrhoea, RLL AFP & Yes, no HFM lesions & ASM & Serum, CSF & $\begin{array}{l}\text { Discharge with } \\
\text { residual deficit }\end{array}$ & $\begin{array}{l}\text { Agent } Y(S I B \cup 97) \\
\text { from serum }\end{array}$ \\
\hline 2 & 8 & Male & May 4 & LUL AFP & Yes, no HFM lesions & ASM & Serum, CSF & $\begin{array}{l}\text { Discharge with } \\
\text { residual deficit }\end{array}$ & $\begin{array}{l}\text { Agent } Y(S I B U 97) \\
\text { from serum }\end{array}$ \\
\hline 3 & 11 & Male & June 24 & $\begin{array}{l}\text { Generalised tonic-clonic } \\
\text { seizure, RUL monoparesis }\end{array}$ & Yes, no HFM lesions & ASM & $\begin{array}{l}\text { Serum, TS, RS, } \\
\text { CSF }\end{array}$ & $\begin{array}{l}\text { Discharge with } \\
\text { residual deficit }\end{array}$ & No growth \\
\hline 4 & 9 & Female & June 26 & LUL AFP & Yes, HFM lesions & ASM & $\begin{array}{l}\text { Serum, TS, } \\
\text { mouth ulcer swab }\end{array}$ & $\begin{array}{l}\text { Discharge with } \\
\text { residual deficit }\end{array}$ & No growth \\
\hline 5 & 14 & Male & June 27 & $\begin{array}{l}\text { Vomiting and lethargy, } \\
\text { developed LLL AFP }\end{array}$ & Yes, HFM lesions & ASM & $\begin{array}{l}\text { Serum, TS, RS, } \\
\text { CSF }\end{array}$ & $\begin{array}{l}\text { Discharge with } \\
\text { residual deficit }\end{array}$ & $\begin{array}{l}\text { Ad } 12 \text { from TS, } \\
\text { RS and CSF, agent } Y \\
\text { from CSF only }\end{array}$ \\
\hline 6 & 19 & Male & July 2 & $\begin{array}{l}\text { Flaccid paralys is of both } \\
\text { lower limbs }\end{array}$ & Yes, no HFM lesions & ASM & $\begin{array}{l}\text { Serum, TS, RS, } \\
\text { CSF }\end{array}$ & .. & Agent $Y$ from CSF \\
\hline 7 & 14 & Female & July 11 & $\begin{array}{l}\text { Altered sensorium, AFP } \\
\text { of both lower limbs, } \\
\text { unstable CVS }\end{array}$ & Yes, HFM lesions & ASM & $\begin{array}{l}\text { Serum, TS, RS, } \\
\text { CSF, stool }\end{array}$ & $\begin{array}{l}\text { Discharge with } \\
\text { improved power }\end{array}$ & $\begin{array}{l}\text { Agent } Y(\text { Ad by IF) } \\
\text { from stool, CSF }\end{array}$ \\
\hline 8 & 4 & Male & August 11 & $\begin{array}{l}\text { Lethargy, vomiting, } \\
\text { altered sensorium, LUL } \\
\text { monoparesis, poor } \\
\text { swallowing, weak gag }\end{array}$ & $\begin{array}{l}\text { Yes, mouth ulcers, } \\
\text { macular rash on arms } \\
\text { and soles of feet }\end{array}$ & ASM & Serum, TS, RS & $\begin{array}{l}\text { Discharge with } \\
\text { improved power }\end{array}$ & No growth \\
\hline
\end{tabular}

Ad=adenovirus; $A S M=$ aseptic meningitis; CSF=cerebrospinal fluid; CVS=cardiovascular system; IF=immunofluorescence; LLL=left lower limb; LUL=left upper limb; RLL=right lower limb; RUL=right upper limb; TS=throat $s$ wab. ${ }^{*}$ All 1997.

Table 2: Non-fatal AFP cases

primer set was 5'-AACATGACCAAAGACTGGTT-3' (forward) and 5'-GCCGAGAAGGGCGTGCGCAGGTA-3' (reverse), and the inner primer set was 5'TTCAGAAACTTCCAGCCCATGAG-3' (forward) and 5'-T C C AT G G G A T C C A C C T CAAAA G T CAT - 3' (reverse). The cycling conditions were $94^{\circ} \mathrm{C}$ for $5 \mathrm{~min}, 30$ cycles of $94^{\circ} \mathrm{C}$ for $45 \mathrm{~s}, 55^{\circ} \mathrm{C}$ for $45 \mathrm{~s}, 72^{\circ} \mathrm{C}$ for $45 \mathrm{~s}$, with a final extension at $72^{\circ} \mathrm{C}$ for $5 \mathrm{~min}$. For the second (nested) $P C R$, the annealing temperature was raised to $60^{\circ} \mathrm{C}$, giving a 349 bp product. We applied this nested PCR to other agent $Y$ cultures and the cumulative results of virus isolation and identification are shown in tables 1 and 2 .

$T$ en of 15 patients with agent $Y$ isolates were positive for adenovirus by immunofluorescence or PCR, or nested $P C R$. The remaining, as yet unidentified, agents isolated from A 549 cells have the same growth characteristics and cytopathic effect in A549 cells as those we identified as adenoviruses, but we have no formal evidence that all these agents are the same.

T able 3 shows the sites that yielded proven enteroviruses and adenoviruses from patients who died. Four enteroviruses and 11 adenoviruses were isolated (some viruses were isolated from multiple sites). T wo of four enteroviruses and ten of 11 adenoviruses were isolated from sterile sites.

In those patients with fatal disease, a third had dual infections. Of those from whom any virus isolates were obtained, half had dual infections. Every child from whom we isolated an enterovirus and who died from the disease also had agent $Y$ or adenovirus.

Since the poor growth of the adenovirus isolates made it difficult to do standard virus neutralisation assays for serotyping, we amplified part of the VA RNA gene using primers described previously $y^{9}$ and obtained a PC R product

\begin{tabular}{lll}
\hline \multicolumn{1}{c}{ Site of isolation } & Enterovirus & Adenovirus \\
\cline { 1 - 1 } Serum & 2 (EV71, echovirus 25) & 2 \\
Cerebrospinal fluid & 0 & 3 \\
Throat swab & 1 & 1 \\
Rectal swab & 1 (EV71) & 0 \\
Cardiac muscle & 0 & 3 \\
Brain & 0 & 1 \\
Lung & 0 & 1 \\
\hline Total & 4 & 11 \\
\hline
\end{tabular}

Table 3: Sites of isolation of enteroviruses and adenoviruses from fatal cases of approximately $500 \mathrm{bp}$, consistent with a subgenus B1 adenovirus. We used the restriction enzyme Taql to obtain a restriction profile of the PCR product (figure 2) and compared it with published profiles ${ }^{9}$ to identify the serotype, but no match was made. The Taql restriction profile obtained from the VA RNA gene PCR product of this virus does not match any of the adenovirus subgenus $B$ prototypes (A Kidd, U mea University, Umea, Sweden, and J de Jong, Erasmus University, Rotterdam, Netherlands, personal communication) and at this stage we have identified SIBU97 to be a subgenus B1 adenovirus, which was also confirmed by the Centers for Disease Control and Prevention ( $M$ Pallansch, CDC, Atlanta, GA, U SA, personal communication).

\section{Discussion}

The deaths of children during a hand, foot, and mouth disease outbreak in Sarawak have raised many questions about this familiar seasonal infection. The deaths were remarkable for their rapidity of onset characterised by severely depressed myocardial contractility on echocardiography and progressive refractory cardiac dysfunction. These deaths, coupled with the observation of associated neurological signs, including seizures, aseptic

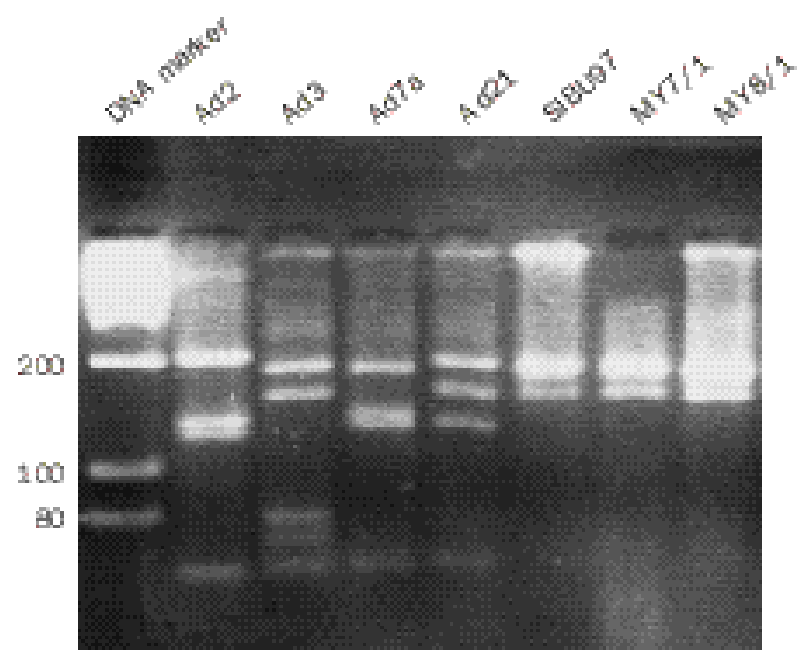

Figure 2: Taql restriction digest profile of VA RNA gene PCR product

All adenoviruses shown are clinical isolates, except $\mathrm{Ad} 21$, which was obtained from the American Type Culture Collection. 
meningitis, and flaccid limb monoplegias in most of these children, gave rise to initial suspicions of a large-scale enterovirus outbreak

The isolation of EV71 from some of the children who died has raised speculation on whether infection with this virus is the cause of death. This assumption has been further strengthened by necropsy findings of significant brain-stem encephalitis, especially since myocardial tissue samples consistently appear normal on light-microscopy examinations (J Dolkadir, Central Medical L aboratory, Sarawak, personal communication). The clinicopathological discordance has led some investigators to believe that neurogenic mechanisms, specifically neurogenic pulmonary oedema, ${ }^{10-12}$ are the cause of the cardiovascular manifestations. However, such explanations, which suggest that the heart was secondarily affected after a primary enteroviral infection of the central nervous system, do not convincingly explain the finding of severely depressed myocardial function (the hallmark of this syndrome). Indeed, we suggest that although infection of the central nervous system is an integral feature, primary myocardial dysfunction is the cause of death.

In the children who died in Sibu, enteroviruses were isolated from only three of 16 , and none of the isolates were from tissue-specific sites that would have increased their clinical importance. The finding that EV71 isolates from clinically similar cases during the EV71 hand, foot, and mouth disease season in Taiwan are genetically distinct from the Sarawak isolates ${ }^{3}$ further diminishes the possibility that EV71 is the agent responsible for both these unusual outbreaks. H owever, we isolated a fastidious agent from A549 cells from various sterile tissue sites in several children who died and subsequently showed this to be subgenus $B$ adenovirus. This finding has considerable implications.

A part from enteroviruses, ${ }^{13}$ adenoviruses are now also suggested to be important causal agents of myocarditis. $M$ artin and co-workers $^{14}$ have shown that adenoviral myocarditis is often associated with histopathologically normal cardiac tissue, which is consistent with our findings. Massive ultrastructural damage of myocardial tissue, mediated by direct viral tissue invasion, or possibly viral toxins ${ }^{15}$ or viral-induced cytokines, ${ }^{16,17}$ probably results in the severe cardiac dysfunction seen in our patients.

$M$ ore remarkable, however, is the isolation of this agent from cerebrospinal fluid samples from children with AF P. Surprisingly, intense efforts to isolate enteroviruses from children who died and children with AFP were unsuccessful. This contrasts with the high rate of isolation of enteroviruses (mainly EV 71, also C oxsackie A 16 virus and echoviruses) in children with uncomplicated hand, foot, and mouth disease. In view of recent findings by Solomon and colleagues, ${ }^{18}$ who linked AFP to Japanese encephalitis virus in Vietnam, we seem to have only a basic knowledge of the aetiologies of some of the viral syndromes prevalent in southeast Asia.

We are therefore confronted with a fastidious, subgenus $B$ adenovirus that can infect tissues of the central nervous system and heart. Isolated infections of the central nervous system probably result in non-fatal AFP. Concurrent myocardial infection probably results in myocardial failure and death. Dual infection with this adenovirus and EV 71 and the temporal association of the deaths with an EV71related hand, foot, and mouth disease season indicate that these agents may interact.

Contributors

See $C$ hang Wong and Shekhar K rishnan managed patients and collected clinical data and samples at Sibu H ospital. Jane Cardosa and Phaik $\mathrm{H}$ ooi $\mathrm{T}$ io processed specimens, and isolated and identified viruses. Jane $\mathrm{C}$ ardosa and David Perera did the molecular biology. The analysis and writing was done by See $\mathrm{C}$ hang Wong, Shekhar K rishnan, and Jane C ardosa. All investigators contributed to the preparation of the paper.

\section{Acknowledgments}

We thank the dedicated team of nurses and technicians who packed and transported specimens during the outbreak; M ohamad T aha A rif (director of the Sarawak H ealth Department) and T an Sri Abu Bakar Sulaiman (Director $\mathrm{G}$ eneral of $\mathrm{H}$ ealth, $\mathrm{G}$ overnment of $\mathrm{M}$ alaysia) for support, encouragement, and permission to publish the findings; $M$ ark Pallansch (CD C, Atlanta, GA, USA) for generously sharing primers; and Zawawi Ismail, G hazally Ismail, Andrew K iyu, Y ao Sik K ing, and Abdul Rahim Abdullah for providing unstinting moral support in a time fraught with tension and exhaustion.

T he work was supported partly by operational funds from the $U$ niversiti $M$ alaysia Sarawak and the Sarawak H ealth D epartment and partly by a grant from the State G overnment of Sarawak, M alaysia.

\section{References}

1 WH O. Outbreak of fatal myocarditis in Sarawak. W kly E pidemiol Rec 1997; 72: 184.

2 WH O. Outbreak of hand, foot and mouth disease in Sarawak. W kly Epidemiol Rec 1997; 72: 211.

3 CDC. D eaths among children during an outbreak of hand, foot and mouth disease-T aiwan, Republic of C hina, A pril-July 1998. M M W R M orb M ortal W kly Rep 1998; 47: 629-32.

4 Allard A, G irones R, Juto P, W adell G. Polymerase chain reaction for detection of adenoviruses in stool samples. J C lin M icrobiol 1990; 28: 2659-67.

5 Romero JR, Rotbart HA. PCR detection of the human enteroviruses. In: Persing, DH , Smith T F, T enover FC, White TJ, eds. D iagnostic molecular microbiology: principles and applications. Washington, DC: American Society for M icrobiology, 1993: 401-06.

6 T anaka M. Rapid identification of flavivirus using the polymerase chain reaction. J V irol M ethods 1993; 41: 311-22.

7 Cardosa M J, F azeha B, Sharifah H, T io PH, N immannitya S. A nitrocellulose membrane based IgM capture enzyme immunoassay for etiological diagnosis of dengue virus infections. Clin D iagn V irol 1995; 3: 343-50.

8 Solomon T, T hao LT, D ung N M , et al. Rapid diagnosis of Japanese encephalitis by using an immunoglobulin $M$ dot enzyme immunoassay. J Clin M icrobiol 1998; 36: 2030-34.

$9 \mathrm{~K}$ idd $\mathrm{AH}$, Jonsson $M, G$ arwicz D, et al. Rapid subgenus identification of human adenovirus isolates by a general PCR. J C lin M icrobiol 1996; 34: $622-27$.

10 Chang $L-Y, H$ uang $Y-C$, L in $T-Y$. F ulminant neurogenic pulmonary oedema with hand, foot and mouth disease. L ancet 1998; 352: 367-68.

11 L um LCS, Wong KT, Lam SK, C hua K B, G oh AYT. N eurogenic pulmonary oedema and enterovirus 71 encephalomyelitis. $L$ ancet 1998; 352: 1391.

12 L um LCS, W ong KT, L am SK, et al. F atal enterovirus 71 encephalomyelitis. J Pediatr 1998; 133: 795-98.

13 Bowles NE, Richardson PJ, O Isen EG J, Archard LC. Detection of Coxsackie $B$ virus specific RN A sequences in myocardial biopsy samples from patients with myocarditis and dilated cardiomyopathy. Lancet 1986; i: 1120-23.

$14 \mathrm{M}$ artin $\mathrm{AB}$, W ebber S, F ricker FJ, et al. Acute myocarditis: rapid diagnosis by PCR in children. Circulation 1994; 90: 330-39.

15 Brandon FB, M cClean IW M Jr. Adenovirus. Adv Virus Res 1962; 9: $157-93$.

16 Y okoyama T, Vaca L, Rossen RD, Durante W, H azarika P $M$ ann DL. C ellular basis for the negative inotropic effects of tumor necrosis factor-alpha in the adult mammalian heart. J Clin Invest 1993; 92: 2303-12.

17 L ibby P, M itchell R N. Cytokines score a knockout: harnessing gene targeting to gain insight into the pathogenesis of myocarditis. Circulation 1997; 95: 551-52.

18 Solomon $T, K$ neen $R, N$ guyen $M D$, et al. Poliomyelitis-like illness due to Japanese encephalitis virus. L ancet 1998; 351: 1094-97. 